\title{
Obstructive Sleep Apnea Syndrome Implications on Health and Adherence to CPAP Treatment
}

\author{
Jesús Moo Estrella, Paulino Dzib Aguilar, Ricardo Castillo Ayuso, \\ Rossana Cuevas Ferrera \\ Department of Psychology, Universidad Autónoma de Yucatán, Mérida, México \\ Email: jmestre@correo.uady.mx
}

Received 20 December 2014; accepted 25 May 2015; published 28 May 2015

Copyright (C) 2015 by authors and Scientific Research Publishing Inc.

This work is licensed under the Creative Commons Attribution International License (CC BY). http://creativecommons.org/licenses/by/4.0/

(c) (i) Open Access

\begin{abstract}
Respiratory disorders during sleep have as a general characteristic the alteration of the respiratory cycle while sleeping. The most outstanding characteristic of Obstructive Sleep Apnea Syndrome (OSA) is the partial (hypopnea) or total (apnea) obstruction of the upper airway that occurs repeatedly during sleep. The OSA is global public health issue. When it is not treated, OSA represents a cost two or three times higher of the institutional resources for health. Studies conducted in different countries indicate that the prevalence of the OSA goes from $2 \%$ to $10 \%$ in general population. The OSA is a serious sleep disorder that has negative implications on multiple systems of the organism. It is associated with hypertension, diabetes and the metabolic syndrome. When OSA coexists with a heart disease or ischemic heart disease, it significantly raises the probability of a heart failure. The use of Continuous Positive Airway Pressure (CPAP) is so far the most effective method for OSA treatment. Intervention at different levels (physiological, educational and psychological intervention) appears to be important in adherence to CPAP treatment.
\end{abstract}

\section{Keywords}

Obstructive Sleep Apnea Syndrome, Health, Continuous Positive Airway Pressure, Adherence, CPAP

\section{Introduction}

The OSA is global public health issue [1]-[3]. When it is not detected and treated opportunely, OSA represents an expense two or three times higher of the institutional resources in health [4] [5]. 
The detection and treatment of the OSA has included the participation of hospitals and universities that have gradually been added to its coverage, mostly due to the acknowledgement of the benefits of OSA treatment in people's different life spheres; these include: the improvement of the medical conditions, the psychological wellbeing, the social and labor relationships, the neuropsychological development and the quality of life. Nonetheless, the actual outlook suggests that there is still much to be done, which in turn suggests the need of forming more professionals specialized in the study of sleep, the reduction of time and costs of diagnosis, and increase treatment adherence strategies [6].

\section{Characteristics of the OSA}

Respiratory disorders during sleep have as a general characteristic the alteration of the respiratory cycle while sleeping. In particular, the most outstanding characteristic of the OSA it's the partial (hypopnea) or total (apnea) obstruction of the upper airway that occurs repeatedly during sleep which frequently leads to a reduction of oxygen saturation in blood and culminates with brief arousals from sleep. By definition, the hypopnea and apnea last at least 10 seconds in adults. Most of the events last 10 to 30 seconds, although in occasions they persist for more than one minute. Obstructions can occur at any stage of sleep, but are more frequentin stage N1, N2 and Rapid Eye Movement (REM) sleep.

In REM sleep respiratory events are more durable and present a major decrease in the oxygen saturation which usually returns to its basal values followed by the normal recuperation of breathing. Snoring betweenapneas is commonly reported by the roommates, who are also witnesses of the gasps, choking and movements that frequently disrupt sleep. Most patients with OSA awake in the morning feeling tired and unrefreshed, despite the duration of their time in bed [7].

\subsection{Prevalence}

Until half century ago the OSA was unknown and undiagnosed. Today it is estimated that $4 \%$ occurs in men and $2 \%$ in women, and that its prevalence increase as it reaches adulthood. Studies conducted in different countries (considering a hypopnea and apnea index $\leq 5$ plus daytime sleepiness report) indicate that the prevalence of the OSA goes from $2 \%$ to $10 \%$ in general population. In Latin America, with these same indicators, the prevalence is $23.5 \%$ [8], having obesity as the main risk factor; in Mexico, OSA tends to be present in $98 \%$ of cases in obese people.

\subsection{OSA Causes}

The direct cause for OSA is the narrowing of the upper airway during sleep and its origin is multifactorial. Patients with OSA have their cross-sectional area of the upper airway reduced due to either excessive bulk of soft tissue (tongue, soft palate and lateral pharyngeal walls), or craniofacial anatomy, or both. Upper airway permeability is dependent on pharyngeal dilating muscles, which decreases with sleep onset (Figure 1). The patency of the upper airway is dependent on the sleep-wake state, the sleep that is the main factor that contributes to the relaxation of the pharyngeal muscles and thus to obstruction of the upper airway [7].

During REM sleep decreases muscle tone including dilation of the pharyngeal muscles, contributing to the increase and severity of apneas and hypopneas. Polysomnography shows that during the OSA continuous the effort of the thorax and abdomen, despite the obstruction of the upper airway.

\section{OSA and Its Implications on Health When Sleeping}

The OSA is a serious sleep disorder that has negative implications on multiple systems of the organism. It is associated with hypertension, diabetes and the metabolic syndrome [9], nonetheless their relations with cardiovascular diseases are acknowledged over the world and in Mexico as a public health problem. As an important matter, when OSA coexists with a heart disease or ischemic heart disease it significantly raises the probability of a heart failure [10].

\subsection{OSA and Cardiovascular Alterations}

OSA modifies the cardiorespiratory function through hypoxemia, micro awakenings (arousal) and intrathoracic 


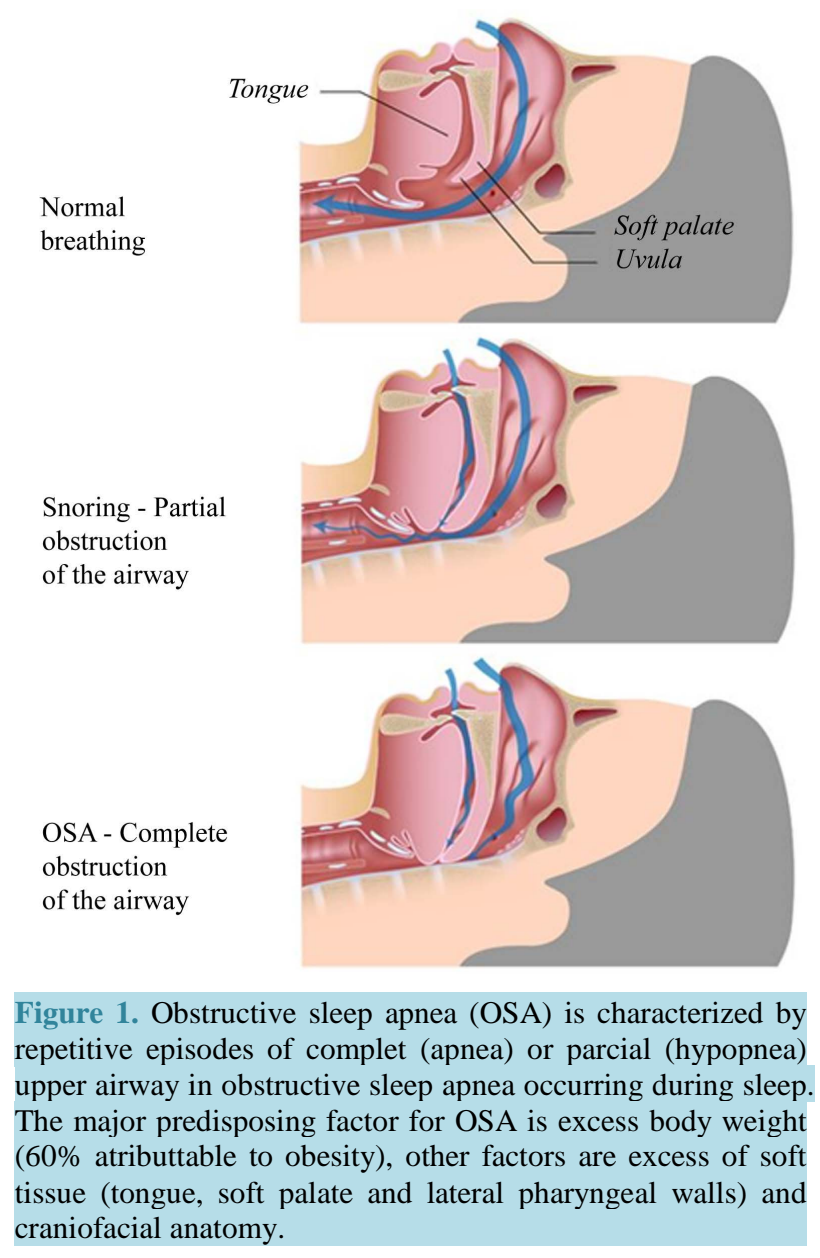

pressure, among others, altering mechanisms including the metabolic, sympathetic activity, systemic inflammation, and right atrial dilatation, that lead to cardiovascular alterations and increases the sudden cardiac death [11] [12]. The OSA triggers a series of mechanisms that lead to cardiovascular alteration, increasing the sudden death risk during the night.

\subsubsection{Hypoxemia}

The abnormal decrease in the partial pressure of oxygen in arterial blood is known as hypoxemia, which is a frequently condition for patients with OSA. Intermittent periods of hypoxia and $\mathrm{CO}_{2}$ retention can alter the hemodynamic and autonomic response of these patients sleep. Acute periods of hypoxemia can activate the pathophysiological mechanisms leading to acute nocturnal cardiac events [13].

\subsubsection{Sympathetic Activation}

Obstructive events during sleep are terminated by the sympathetic activation or arousal, which are accompanied with the increase of it [14]. The causes for sympathetic overactivation are still uncertain [15], however, data obtain from both animals and humans suggest that hypoxia intermittent cycle (ICH) derived from the OSA, can be the bridge to explain the relationship between the obstruction of the upper airway during sleep and sympathetic activation that is maintained even during wakefulness [16]. Sympathetic nervous system overactivity partly explains the high arterial pressure observed in OSA patients [17].

\subsubsection{Systemic Alterations}

Systemic disturbances are provoked by the ventilatory overexertion generated in the struggle to breath with an obstructed airway. The inspiratory effort to release airway resistance during sleep maybe higher than dyspnea 
that occurs with intense physical exertion on wakefulness [18]. The intrathoracic pressure increases the transmural gradients, affecting the atrial functions, and favors ventricular growth [19]-[21] and the risk of aortic dissection [22] [23].

\subsubsection{Arterial Hypertension}

OSAis associated with many cardiovascular diseases, including arrhythmias and hypertension [24]-[27]. OSA increases three times the risk of hypertension, independently of obesity and other comorbidities [28]. By contrast, OSA can be present in 70\% ofpatients initially detected with resistant arterial hypertension [29] [30]. The intermittent hypoxia, chemoreceptor stimulation, sympathetic and renin-angiotensin system activation are proposed as the main mechanisms linking OSA with hypertension [11] [31].

Intrathoracic pressure changes lead to excessive activation of the stress mechanism on the heart and artery walls; reflex sympathetic activation induced by these changes generates repetitive increments in blood pressure [32].

\subsubsection{Endothelial Dysfunction}

The endothelium is strategically located in blood and tissues, whose dysfunction indicates a loss of the homeostatic functions of blood vessels [33] [34]. In patients with OSA the intermittent hypoxias leads to arousals and oxygen desaturation/reoxygenation facilitating inflammation and oxidative stress, which in turn reduces the nitric oxide concentration, thereby contributing to endothelial dysfunction and consequently to cardiovascular disorders [35] [36].

\subsubsection{Intrathoracic Pressure Changes}

The closure of the upper airway in apnea episodes generates abrupt and repetitive changes of inspiratory effort, producing negative intrathoracic pressure changes that increase transmural gradients across the atria, ventricles and aorta [37] [38]. Thereby, intrathoracic pressure changes lead to autonomic and hemodynamic instability contributing to the development of atrial fibrillation and heart failure in patients with OSA [39]-[41].

\subsubsection{Myocardial Ischemia}

Myocardial ischemia is a condition in which coronary blood flow is insufficient to maintain the aerobic metabolism of the myocardium, establishing an anaerobic metabolism and ultimately cell death by lack of oxygen.OSA precipitates myocardial ischemia or MI [42]-[44], significantly increasing the probability of sudden cardiac death observed in patients with OSA [45]. The post-apneic reoxygenation and intermittent hypoxia are possible causes of myocardial ischemia [42] [46].

\subsubsection{Cardiac Insufficiency}

Diastolic dysfunction and systolic heart insufficiency are closely related to OSA. Obstructive events may occur hundreds of times during sleep, and on each one inspiratory negative intrathoracic pressure caused by the occluded upper airway (AW) increases heart insufficiency in patients with OSA [47]

\section{Diagnostic Criteria for Obstructive Apnea in Adults}

OSA is diagnosed by polysomnography and clinical symptoms of the patient; in Table 1 are presented the standard diagnostic criteria. Polysomnography is the reference test (ICSD-3, 2014).

Patients and physicians can identify a number of signs and symptoms related to the presence of OSAS, these include the report of the couple or family indicating that the patient: has respiratory pauses, snore between every pauses, episodes of gasping or choking and movements that disrupt sleep [34]. Likewise, indicate that respiratory disturbances during sleep may be exacerbated following the ingestion of alcohol, use of sedating medications prior to sleep, or following an increase in body weight. Meanwhile the patient reports: fatigue of awakening, daytime sleepiness, impaired cognitive performance and consequently your work performance. Likewise, the presence of medical conditions such as obesity, hypertension, type 2 diabetes and impaired heart, together allow suspect the presence of OSA in patients [31].

Nonetheless, the effort aimed at improving efficiency in time and cost of diagnosis and treatment for OSA has enabled the development of simplified systems, such as respiratory polygraphy [48]. These systems can be useful considering the economic context of countries like Mexico [49], even if they require further research on its 
Table 1. Standard diagnostic criteria for obstructive sleep apnea in adults.

Diagnostic criteria

(A and B) or C satisfy the criteria

\section{A) The presence of one or more of the following:}

1. The patient complains of sleepiness, nonrestorative sleep, fatigue, or insomnia symtoms.

2. The patient wake with breath holding, gasping, or choking.

3. The bed partner or other observer reports habitual snoring, breathing interruptions, or both during the patient's sleep.

4. The patient has been diagnosed with hypertension, a mood disorder, cognitive dysfunction, coronary artery disease, stroke, congestive heart failure, atrial fibrillation, or type 2 diabetes mellitus.

B) Polysomnography (PSG) or out of center sleep testing (OCST) demonstrates:

1. Five or more predominantly obstructive respiratory events (obstructive and mixed apneas, hypopneas, or respiratory effort related arousal (RERAs) per hours of sleep during a PSG or per hours of monitoring (OCST).

OR

\section{C) PSG or OCST demonstrates:}

1. Fifteen or more predominantly obstructive respiratory events (apneas, hypopneas, or RERAs) per hour of sleep during a PSG or per hour of monitoring (OCST).

Notes:

1. OCST commonly underestimates the number of obstructive respiratory event per hour as compared to PSG because actual sleep time, as determined primarily by EEG, is often not recorded. The term respiratory event index (REI) may be used to denote event frequency based on monitoring time rather than total sleep time.

2. Respiratory events defined according the latest version of the AASM Manual for the Scoring of Sleep and Associated Events.

3. RERAs and hypopneas events based on arousal from sleep cannot be scored using OCST because arousals by EEG criteria cannot be identified.

scopes and limitations. The screening by questionnaires has also been included as a useful tool in the initial process of OSA detection [50]-[52].

\section{OSA Treatments and Health Psychology Role}

Sleep respiratory alterations treatment includes methods such as surgery or mandibular devices [53]-[55]; however, the use of Continuous Positive Airway Pressure (CPAP) is so far the most effective method for OSA treatment [56]. OSA treatment with CPAP is useful only for the night that is used, improving respiratory condition while the person is asleep, which allows the increase of sleep efficiency, however, some patients have troubles adhering to this treatment, which reduces its effectiveness, which is why health psychology comes to play a role of great importance.

In this sense, CPAP represents an effective treatment but with highly variable adherence percentages [57]. OSA treatment with CPAP reduces blood pressure, arrhythmias, daytime sleepiness, improves left ventricular function and cognitive performance. However, CPAP only "cure” patients while they use it and many of them have a notorious difficulty accepting its use. This is why patients with OSA, besides receiving physiological treatment, also require educational and psychological intervention. Intervention at different levels appears to be important in adherence to CPAP treatment.

\subsection{Associated Factors with CPAP Adherence}

CPAP adherence data indicates that the initial stage of treatment, at least in the first week is a critical period in which patients decide whether to continue or not using it [58]. Patients who use CPAP in the initial stages of treatment have more chances to adhere to treatment and continuing its long-term use [59]. This suggests as a necessary requisite to identify newly diagnosed patients who have less probabilities of using CPAP in the initial stages of treatment. Thus, previous interventions and the start of treatment with these patients may help increase 
their adherence to CPAP and continue its use in long term. Educational programs at the beginning of OSA treatment seem to be the key to CPAP adherence [60] nonetheless CPAP use decreases with time [61], which raises the need to define the content of programs that improve adherence, including their long term use.

Regarding OSA characteristics, it have been identified several variables associated with their use. It has been found, for example, that patients have more chances of using CPAP when they present a higher hypopnea and apnea index, daytime sleepiness and low rates of nocturnal oxyhemoglobinsaturation [62]. Probably CPAP adherence in this group of patients is because the positive effects of treatment are more evident compared with those with slight or moderate levels of apneas and hypopneas. In this regard, it is believed that patients with a higher apnea and hypopnea index can better distinguish the reduction of the subsequent clinical symptoms of CPAP treatment, therefore, maintaining its use for a longer time.

Besides considering the previously issues, it can be assure that CPAP acquisition is the first obstacle to overcome, as suggested by a study of 304 patients from a public referral hospital. The study reports that half of these patients, who were prescribed to use CPAP, did not acquire their treatment equipment. Patients who acquired their CPAP equipment (55\%) were identified with the highest severe apnea and hypopnea indexes and they counted with social security to acquire their equipment. The average time for acquisition of their equipment was a month and a half. However, the majority (80\%) of patients who acquired their equipment continued using them, even after up to34 months [49].

Moreover, it is also important to note that half of the patients who acquire CPAP complained of discomfort related to its use, for example, they complained about nasal congestion, dry mouth or skin irritation. This group of patients can be helped to maintain their adherence to treatment by receiving guidance about their problem, which focuses on increasing knowledge concerning functioning and care about CPAP use.

Other aspects that can be taken to account about adherence to OSA treatment, are the implementation of new technologies in CPAP equipment, such as the automatic valuation equipment's and bi-level units, as well as the design and materials used in masks, which improve patients comfort by making their use friendlier [57] [63].

In addition to the effort to identify OSA characteristics to improve its treatment, some researches have focused on personality characteristics that may influence both the diagnosis and treatment of respiratory alterations during sleep [64]. These investigations suggest that hypochondriasis and psychopathy are two personality characteristics commonly associated with OSA, and that they modify diurnal functioning of these patients [65][67]. Similarly, the mood disorders, especially depression, can also be observed in patients with respiratory alterations during sleep. Depression is considered as an independent factor that increases fatigue [68] and sleepiness [69], in addition to the typical symptoms of a patient with OSA. Identification of personality and mood characteristics and their additional treatment to OSA treatment, can be reduced by daytime symptoms such as fatigue and sleepiness reported in this group of patients [70]-[72].

A second group of factors associated with the patient's psychological characteristics that affects CPAP adherence are the cognitive factors [73], that is, the perception and meaning that they have about CPAP use, which playthe key role in the decision of using it or avoid it [74]. These cognitive factors include: the patient analysis done on the expectations he has of the outcome, the perception of his self-efficacy, social support, the specific knowledge he has about OSA and CPAP, the balance in decision-making and psychological flexibility openness to change [63] [74]-[77].

\subsection{Cognitive Factors Associated with CPAP Adherence}

Cognitive schemes have an important role in adherence to OSA treatment by CPAP [73] [78]. Here are two useful theoretical proposals to predict CPAP adherence.

\subsection{Messages with Positive and Negative Framing}

From the cognitive theory of health, a way to directly influence in decision-making for CPAP use is by the framing of messages that are given to the patient about CPAP use. In this sense, the information can be presented in a positive (in terms of profits) or negative (in terms of losses) frame about using or not CPAP, respectively [79]. Prospect Theory (PT) states that people change their current position regarding an event, in terms of potential gains or losses. Both options don't have the same emotional weight, as the intensity of displeasure at a loss exceeds the intensity of the pleasure for potential profit. Under this scheme, the PT predicts that in situations with a neutral starting point, the preference for options with uncertain results and that involve risks is influenced by 
the frame within which the information is presented.

If the current situation is considered as a gain, the decision is more reluctant to risk in order to avoid a loss. Moreover, if the current situation is considered as a loss, the decision is inclined to accept the risk to try to recover what has been lost. In the case of CPAP adherence, if patients do not perceive treatment to be important or associated with a type of loss, they will hardly use it. That is, the patient does not adhere when treatment information is not consistent or does not include the consequences for not using CPAP [80]. The PT applied to OSA treatment adherence suggests that CPAP use decision making is influenced by the way information is presented to the patient. Presenting information in terms of consequences (negative messages) for not using CPAP increases the adherence possibility [80]. Table 2 provides some examples of messages with positive and negative framing.

\subsection{Irrational Beliefs}

Irrational beliefs are part of the theoretical model of Ellis [81], who proposes that mental representations and beliefs are the causal agents of behavior. In this sense, beliefs may be to certain degree rational or irrational; former beliefs are characterized by thoughts that promote the persons wellbeing and include thoughts in which aversive situations are evaluated in a flexible, tolerant way and with acceptance of the self or the situation ability. On the other hand, irrational thoughts are characterized for been associated with the origin of emotional, behavioral and interpersonal disorders that include demanding, absolutist and inflexible psychological schemes.

The authors of this study suggest that beliefs about CPAP use, theoretically predicts patients disposition to acquire the equipment and adherence to treatment. Therefore, patients with irrational beliefs on CPAP, such as: "CPAP is unbearable and terrible, I could never use it", will start with a psychological barrier that prevents them from accepting the situation and be flexible to the possibility of gradually using the CPAP. Nonetheless, irrational beliefs about CPAP use can be identified, allowing patient's reorientation towards alternative thoughts, more realistic, flexible and tolerable. Table 3 presents a list of irrational beliefs commonly identified in clinical practice.

A future working hypothesis, that will have to be demonstrated, is that these patients group will probably have more irrational beliefs, partly because neuropsychological bases that serve as a platform for the development of the flexible, scientific and realistic thinking are altered as a result of OSA.

\section{Neuropsychological Changes Associated with OSA}

Different studies indicate that OSA alters cognitive functioning, affecting processes such as: attention, arousal, memory, psychomotor performance and executive functions. It is believed that daytime sleepiness and hypoxemia associated with OSA may be the factors that alter the cognitive functions; although it has also been proposed that the OSA comorbid alterations, such as cardiovascular diseases, obesity and physical inactivity may be

Table 2. Educational messages with positive and negative framings about CPAP use.

Positive messages:

If you use CPAP for at least 4 hours:

1. It will decrease your daytime sleepiness and give you more energy.

2. It will have benefits that can save your life.

3. It might help you reduce arterial pressure.

4. It will decrease the heart insufficiency risk.

Negative messages:

If you don't use CPAP for at least 4 hours:

1. You will be sleepy and without energy

2. You are not treating your OSA and can risk your life.

3. You lose the chance of reducing your arterial pressure.

4. It raises the probability of worsening your heart insufficiency. 
Table 3. Irrational beliefs and alternative thoughts about the use of CPAP.

\begin{tabular}{|c|c|}
\hline Irrational belief & Alternative \\
\hline I have not accepted yet that I need to use CPAP. & $\begin{array}{l}\text { Although initially I did not like the idea, I decided that I would regularly } \\
\text { use CPAP. }\end{array}$ \\
\hline Using CPAP is something that shouldn't be happening to me. & I understand that there is no reason to deny that CPAP is present in my life. \\
\hline Using CPAP makes me think that I'm worth less than others. & Those who use CPAP have the same value as the others. \\
\hline It is horrible to know or think that I have to use the CPAP. & $\begin{array}{l}\text { Although CPAP is uncomfortable to use at first, is not that horrible to } \\
\text { use it or think about it. }\end{array}$ \\
\hline It is unbearable to know that I have to use the CPAP. & Using CPAP is uncomfortable but not unbearable. \\
\hline Others will reject me when they know I have to use CPAP. & $\begin{array}{l}\text { I do not think others will criticize or disapprove me for using CPAP and if so, } \\
\text { I will keep using it. }\end{array}$ \\
\hline It is my fault having to use CPAP. & $\begin{array}{l}\text { Having to use CPAP is not something that I feel guilty about, it is } \\
\text { uncomfortable but it helps me be more healthy. }\end{array}$ \\
\hline I should not feel upset or blame me for using CPAP. & $\begin{array}{l}\text { Although sometimes I would feel upset or guilty of having to use CPAP, } \\
\text { I should keep using it for my health. }\end{array}$ \\
\hline \multirow[t]{5}{*}{$\begin{array}{l}\text { I'm upset with myself because I'm not like the others who } \\
\text { do not have to use CPAP. }\end{array}$} & Though unlike most I use CPAP, I'm not mad at me for it. \\
\hline & Other alternative thinking that may help patients \\
\hline & $\begin{array}{l}\text { I can bear to have to use CPAP, though I know it can be difficult or } \\
\text { uncomfortable. }\end{array}$ \\
\hline & $\begin{array}{l}\text { I would really like not to use CPAP, but I accept that things are not always } \\
\text { what I desire. }\end{array}$ \\
\hline & $\begin{array}{l}\text { It is unpleasant and unfortunate to know that I have to use CPAP, but is not } \\
\text { terrible. }\end{array}$ \\
\hline
\end{tabular}

more important factors than sleep apnea itself in cognitive functioning changes [82] [83].

A meta-analysis study suggests that OSA affects the attention/wakefulness levels, visual and verbal long term memory, visuospatial and constructional abilities and executive functions. Moreover, data appears to be ambiguous about the effects on working memory, short-term memory and overall cognitive functioning. Attention/ wakefulness decrease appears to be associated with sleep fragmentation and global cognitive functioning with hypoxemia. OSA treatment improves executive dysfunction, attention/wakefulness, visual and verbal long term memory, and global executive functioning too [84].

Rational and irrational beliefs are cognitive processes associated with executive functions. Psychology has shown interest in the impact of OSA on them, which refers to the ability to organize, maintain and develop an objective, with a flexible approach to problem solving, as well as the individual characteristics to adapt basic skills to the extreme, complex and changing environments; the executive functions are related to the prefrontal cortex activity. This brain area is also more vulnerable to OSA, presenting chemical and structural changes [85], that are related to executive functions alterations. Under these conditions the ability to apply cognitive skills functionally decreases, providing the conditions for irrational beliefs to appear.

\section{General Measures in OSA Treatment}

Weight loss is primarily the most accurate recommendation for patients, as reductions in $5 \%$ to $10 \%$ help reduce hypopneas and apneas rates, besides improving symptoms. However, weight reduction involves a change in the eating habits and physical activity, which in most cases patients do not commit to perform. Since it is a strategy with large positive impact on health, it is a goal that should not be abandoned and that have to be promoted with more vigorous measures for its achievement. Other measures include avoiding sedatives and hypnotics that can aggravate the OSA problem, and also avoid alcohol and tobacco intake, which promote and exacerbate the OSA problem, especially when consumed before sleep. Some patients present obstructive events only when they adopt the supine position, and all patients with OSA that sleep in supine position will increase OSA severity; in these patients, it is suggested to adopt the lateral position or increase the height of pillow [48]. 
Table 4. Recommendations in the treatment of OSAS and percentage of effectiveness.

\begin{tabular}{|c|c|c|}
\hline Treatment of OSA & $\%$ AHI reduction & Authors \\
\hline Continuous positive airway pressure (CPAP) treatment [86] & $95 \%$ & Becker (2003) \\
\hline Decreaseof bodyweight [87] [88] & $76 \%-80 \%$ & Tuomilehto, (2009, 2014) \\
\hline Bariatric surgery [89] [90] & $29 \%-71 \%$ & Ashrafian (2014), Bhattacharjee (2013). \\
\hline Uvulopalatopharyngoplastywithtonsillectomy [91] [92] & $19 \%-64 \%$ & Baradaranfar (2015), Boyd (2013). \\
\hline System for hypoglossal nerve stimulation [93] [94] & $50 \%-57 \%$ & Eastwood (2011), Certal (2014). \\
\hline $\begin{array}{l}\text { Positional therapy lateral or prone positioning in the } \\
\text { treatment of mild to moderate OSA. } \\
\text { Mattress and pillow for prone positioning [95]-[99] }\end{array}$ & $50 \%-56 \%$ & $\begin{array}{l}\text { Mador (2005), Heinzer (2012), } \\
\text { Ravesloot, (2013), Afrashi, (2015), } \\
\text { Bidarian-Moniri (2015). }\end{array}$ \\
\hline Mandibular advancementdevices (MADs) [100] [101] & $50 \%-53 \%$ & Mehta A (2001), Levendowski (2007) \\
\hline Drug therapy: Mirtazapine, uptake Serotonin, Others [102]-[104] & $24 \%-52 \%$ & Carley (2007), Kraiczi (1999), Mason (2013). \\
\hline $\begin{array}{l}\text { Oral appliances (OAs) are indicated for use in patients with mild } \\
\text { to moderate OSA (depends mainly on the balance between } \\
\text { the perception of benefit and the side effects) [105] [106] }\end{array}$ & $17 \%-50 \%$ & Fernandez (2007), Sutherland (2014). \\
\hline Exercise [107] [108] & $11 \%-32 \%$ & $\begin{array}{l}\text { Ashrafian (2014), Kline (2011), } \\
\text { Iftikhar (2014). }\end{array}$ \\
\hline
\end{tabular}

The main recommendations for OSAS treatment and its effectiveness (\% AHI reduction) are listed in Table 4.

\section{References}

[1] Mannarino, M.R., Di Filippo, F. and Pirro, M. (2012) Obstructive Sleep Apnea Syndrome. European Journal of Internal Medicine, 23, 586-593. http://dx.doi.org/10.1016/j.ejim.2012.05.013

[2] Philip, P., Sagaspe, P., Lagarde, E., Leger, D., Ohayon, M.M., Bioulac, B., et al. (2010) Sleep Disorders and Accidental Risk in a Large Group of Regular Registered Highway Drivers. Sleep Medicine Reviews, 11, 973-979. http://dx.doi.org/10.1016/j.sleep.2010.07.010

[3] Phillipson, E.A. (1993) Sleep Apnea. A Mayor Public Health Problem. New England Journal of Medicine, 328, 12711273. http://dx.doi.org/10.1056/NEJM199304293281712

[4] Leger, D., Bayon, V., Laaban, J.P. and Philip, P. (2011) Impact of Sleep Apnea on Economics. Sleep Medicine Reviews, 30, 1-8.

[5] Ronald, J., Delaive, K., Roos, L., Manfreda, J., Bahammam, A. and Kryger, M.H. (1999) Health Care Utilization in the 10 Years Prior to Diagnosis in Obstructive Sleep Apnea Patients. Sleep, 2, 225-229.

[6] De la Llata-Romero, M., Castorena-Maldonado, A., Corsi-Cabrera, M., Díaz, M., Haro-Valencia, R., Jiménez-Genchi, A., et al. (2011) Sleep Medicine: Development, Contributions and Perspectives: Report of the Work Group on Sleep Medicine. Revista de Investigación Clínica, 63, 90-99.

[7] American Academy of Sleep Medicine (2014) International Classification of Sleep Disorders. 3rd Edition, ICSD-3, AASM Resource Library [Online].

[8] Torre-Bouscoulet, L., Vázquez-García, J.C., Muiño, A., Márquez, M., López, M.V., de Oca, M.M., et al. (2008) Prevalence of Sleep Related Symptoms in Four Latin American Cities. Journal of Clinical Sleep Medicine, 4, 579-585.

[9] Rajagopalan, N. (2012) Obstructive Sleep Apnea: Not Just a Sleep Disorder. Journal of Postgraduate Medicine, 57, 168-175. http://dx.doi.org/10.4103/0022-3859.81866

[10] Alva, P.J. (2009) Consecuencias metabólicas y cardiovasculares del síndrome de apnea obstructiva del sueño. Medicina Interna de México, 25, 116-128.

[11] Das, A.M. and Khan, M. (2012) Obstructive Sleep Apnea and Stroke. Expert Review of Cardiovascular Therapy, 10, 525-535. http://dx.doi.org/10.1586/erc.12.25

[12] Torre-Bouscoulet, L., Meza-Vargas, M.S., Castorena-Maldonado, A. and Pérez-Padilla, R. (2008) Cardiovascular Risk among Adults with Obstructive Sleep Apnea Syndrome. Gaceta Médica de México, 144, 323-332.

[13] Foster, G.E., Poulin, M.J. and Hanly, P.J. (2007) Intermittent Hypoxia and Vascular Function: Implications for Obstructive Sleep Apnea. Experimental Physiology, 92, 51-65. http://dx.doi.org/10.1113/expphysiol.2006.035204 
[14] Schulz, R. (2010) Obstruction of the Upper Airways in Humans and Animal Models. Pneumologie, 64, 447-449. http://dx.doi.org/10.1055/s-0030-1255511

[15] Fletcher, E.C. (2003) Sympathetic over Activity in the Etiology of Hypertension of Obstructive Sleep Apnea. Sleep, 1, 15-19.

[16] Gilmartin, G.S., Lynch, M., Tamisier, R. and Weiss, J.W. (2010) Chronic Intermittent Hypoxia in Humans during 28 Nights Results in Blood Pressure Elevation and Increased Muscle Sympathetic Nerve Activity. American Journal of Physiology and Heart Circulatory Physiology, 299, 925-931. http://dx.doi.org/10.1152/ajpheart.00253.2009

[17] Charkoudian, N. and Rabbitts, J.A. (2009) Sympathetic Neural Mechanisms in Human Cardiovascular Health and Disease. Mayo Clinic Proceedings, 84, 822-830. http://dx.doi.org/10.4065/84.9.822

[18] Banzett, R.B., Pedersen, S.H., Schwarstein, R.M. and Lansing, R.W. (2008) The Affective Dimension of Laboratory Dyspnea. Air Hunger Is More Unpleasant than Work/Effort. American Journal of Respiratory and Critical Care Medicine, 177, 1384-1390. http://dx.doi.org/10.1164/rccm.200711-1675OC

[19] Altintas, N., Aslan, E., Helvaci, A. and Malhotra, A. (2012) Relationship between Obstructive Sleep Apnea Severity Index and Left Ventricular Function and Volume. Annals of Saudi Medicine, 32, 384-390. http://dx.doi.org/10.5144/0256-4947.2012.384

[20] Baguet, J.P., Barone-Rochette, G., Lévy, P., Vautrin, E., Pierre, H., Ormezzano, O., et al. (2010) Left Ventricular Diastolic Dysfunction Is Linked to Severity of Obstructive Sleep Apnea. European Respiratory Journal, 36, 1323-1329. http://dx.doi.org/10.1183/09031936.00165709

[21] Wachter, R., Lüthje, L., Klemmstein, D., Lüers, C., Stahrenberg, R., Edelmann, F., et al. (2013) Impact of Obstructive Sleep Apnoea on Diastolic Function. European Respiratory Journal, 41, 376-383.

[22] Hata, M., Yoshitake, I., Wakui, S., Unosawa, S., Takahashi, K., Kimura, H., et al. (2012) Sleep Disorders and Aortic Dissection in a Working Population. Surgery Today, 42, 403-405. http://dx.doi.org/10.1007/s00595-011-0060-1

[23] Inami, T., Seino, Y. and Mizuno, K. (2012) Untreated Severe Obstructive Sleep Apnoea and Development of Acute Aortic Dissection. BMJ Case Reports, in Press.

[24] Doonan, R.J., Scheffler, P., Lalli, M., Kimoff, R.J., Petridou, E.T., Daskalopoulos, M.E., et al. (2011) Increased Arterial Stiffness in Obstructive Sleep Apnea: A Systematic Review. Hypertension Research, 34, 23-32. http://dx.doi.org/10.1038/hr.2010.200

[25] Haas, D.C., Foster, G.L., Nieto, F.J., Redline, S., Resnick, H.E., Robbins, J.A., et al. (2005) Age-Dependent Associations between Sleep-Disordered Breathing and Hypertension: Importance of Discriminating between Systolic/Diastolic Hypertension and Isolated Systolic Hypertension in the Sleep Heart Health Study. Circulation, 111, 614-621. http://dx.doi.org/10.1161/01.CIR.0000154540.62381.CF

[26] Lurie, A. (2011) Cardiovascular Disorders Associated with Obstructive Sleep Apnea. Advances in Cardiology, 46, 197-266. http://dx.doi.org/10.1159/isbn.978-3-8055-9646-6

[27] Nieto, F.J., Young, T.B., Lind, B.K., Shahar, E., Samet, J.M., Redline, S., et al. (2000) Association of Sleep-Disordered Breathing, Sleep Apnea and Hypertension in a Large Community-Based Study. Sleep Heart Health Study. Journal of the American Medical Association, 283, 1829-1836. http://dx.doi.org/10.1001/jama.283.14.1829

[28] Peppard, P.E., Young, T., Palta, M. and Skatrud, J. (2000) Prospective Study of the Association between Sleep-Disordered Breathing and Hypertension. New England Journal of Medicine, 342, 1378-1384. http://dx.doi.org/10.1056/NEJM200005113421901

[29] Goncalves, S., Martinez, D., Gus, M., de Abreu-Silva, O., Bertoluci, C., Dutra, I., et al. (2007) Obstructive Sleep Apnea and Resistant Hypertension: A Case-Control Study. Chest Journal, 132, 1858-1862. http://dx.doi.org/10.1378/chest.07-1170

[30] Logan, A.G., Perlikowski, S.M., Mente, A., Tisler, A., Tkacova, R., Niroumand, M., et al. (2001) High Prevalence of Unrecognized Sleep Apnoea in Drug-Resistant Hypertension. Journal of Hypertension, 119, 2271-2277. http://dx.doi.org/10.1097/00004872-200112000-00022

[31] Pedrosa, R.P., Krieger, E.M., Lorenzi-Filho, G. and Drager, L.F. (2011) Recent Advances of the Impact of Obstructive Sleep Apnea on Systemic Hypertension. Arquivos Brasileiros de Cardiologia, 97, 40-47.

[32] Kohler, M. and Stradling, J.R. (2010) Mechanisms of Vascular Damage in Obstructive Sleep Apnea. National Review of Cardiology, 7, 677-685. http://dx.doi.org/10.1038/nrcardio.2010.145

[33] Díaz Juárez, J.A. and Flores Echavarría, R. (2006) Disfunción endotelial: Aspectos fisiológicos y clínicos del endotelio. Revista de Ciencias Clínicas, 7, 64-72.

[34] Lurie, A. (2011) Endothelial Dysfunction in Adults with Obstructive Sleep Apnea. Advances in Cardiology, 46, 139170. http://dx.doi.org/10.1159/isbn.978-3-8055-9646-6

[35] Lavie, L. (2012) Oxidative Stress Inflammation and Endothelial Dysfunction in Obstructive Sleep Apnea. Frontiers in 
Bioscience, 1, 1391-1403. http://dx.doi.org/10.2741/E469

[36] Lui, M.M., Lam, D.C. and Ip, M.S. (2013) Significance of Endothelial Dysfunction in Sleep-Related Breathing Disorder. Respirology, 18, 39-46.

[37] Baguet, J.P., Minville, C., Tamisier, R., Roche, F., Barone-Rochette, G., Ormezzano, O., et al. (2011) Increased Aortic Root Size Is Associated with Nocturnal Hypoxia and Diastolic Blood Pressure in Obstructive Sleep Apnea. Sleep, 34, 1605-1607. http://dx.doi.org/10.5665/sleep.1406

[38] Saruhara, H., Takata, Y., Usui, Y., Shiina, K., Hashimura, Y., Kato, K., et al. (2012) Obstructive Sleep Apnea as a Potential Risk Factor for Aortic Disease. Heart Vessels, 27, 66-73. http://dx.doi.org/10.1007/s00380-011-0135-3

[39] Gami, A.S. and Somers, V.K. (2008) Implications of Obstructive Sleep Apnea for a Trial Fibrillation and Sudden Cardiac Death. Journal of Cardiovascular Electrophysiology, 19, 997-1003. http://dx.doi.org/10.1111/j.1540-8167.2008.01136.x

[40] Loomba, R.S. and Arora, R. (2012) Obstructive Sleep Apnea and Atrial Fibrillation: A Call for Increased Awareness and Effective Management. American Journal of Therapeutics, 19, 21-24. http://dx.doi.org/10.1097/MJT.0b013e3181e70c49

[41] Penzel, T., Sogorski, S., Zelmer, J., Fietze, I., Vogtmann, T., Baumann, G., et al. (2012) Sleep-Disordered Breathing and Atrial Fibrillation. Herzschrittmacherther Elektrophysiology, 23, 14-21.

[42] Kasai, T. (2012) Sleep Apnea and Heart Failure. Journal of Cardiology, 60, 78-85. http://dx.doi.org/10.1016/j.jjcc.2012.05.013

[43] Kim, S.J., Kuklov, A., Kehoe, R.F. and Crystal, G.J. (2008) Sleep-Induced Hypotension Precipitates Severe Myocardial Ischemia. Sleep, 31, 1215-1220.

[44] Verrier, R.L., Muller, J.E. and Hobson, J.A. (1996) Sleep, Dreams, and Sudden Death: The Case for Sleep as an Autonomic Stress Test for the Heart. Cardiovascular Research, 31, 181-211. http://dx.doi.org/10.1016/0008-6363(95)00211-1

[45] Lee, C.H., Khoo, S.M., Chan, M.Y., Wong, H.B., Low, A.F., Phua, Q.H., et al. (2011) Severe Obstructive Sleep Apnea and Outcomes Following Myocardial Infarction. Journal of Clinical Sleep Medicine, 15, 616-621. http://dx.doi.org/10.5664/jcsm.1464

[46] Kawanishi, Y., Ito, T., Okuda, N., Emura, N., Hayashi, T., Futai, R., et al. (2009) Alteration of Myocardial Characteristics and Function in Patients with Obstructive Sleep Apnea. International Journal of Cardiology, 133, 129-131. http://dx.doi.org/10.1016/j.ijcard.2007.08.132

[47] Kasai, T. and Bradley, D. (2011) Obstructive Sleep Apnea and Heart Failure: Pathophysiologic and Therapeutic Implications. Journal of the American College of Cardiology, 57, 119-127. http://dx.doi.org/10.1016/j.jacc.2010.08.627

[48] Durán Cantolla, J. (2010) Síndrome de apneas hipopneas del sueño. In: En, L., Arata, A. and Franceschini, C.M., Eds., Ventilación Mecánica, Buenos Aires, 168-177.

[49] Torre-Bouscoulet, L., López-Escárcega, E., Castorena-Maldonado, A., Vázquez-García, J.C., Meza-Vargas, M.S., Pérez-Padilla, R., et al. (2007) Continuous Positive Airway Pressure Used by Adults with Obstructive Sleep Apneas after Prescription in a Public Referral Hospital in Mexico City. Archivos de Bronconeumología, 43, 16-21. http://dx.doi.org/10.1016/S1579-2129(07)60015-9

[50] Jiménez-Correa, U., Haro, R., González-Robles, R.O. and Velázquez-Moctezuma, J. (2011) How Is the Epworth Sleepiness Scale Related with Subjective Sleep Quality and Polysomnographic Features in Patients with Sleep-Disordered Breathing? Sleep and Breathing, 15, 513-518. http://dx.doi.org/10.1007/s11325-010-0372-1

[51] Massierer, D., Martinez, D., Fuchs, S.C., Pellin, P.P., Garcia, M.S., Zacharias, A.L., et al. (2012) Obstructive Sleep Apnea, Detected by the Berlin Questionnaire: An Associated Risk Factor for Coronary Artery Disease. Cadernos de Saúde Pública, 28, 1530-1538. http://dx.doi.org/10.1590/S0102-311X2012000800011

[52] Romero-López, Z., Ochoa-Vázquez, M.D., Mata-Marín, J.A., Ochoa-Jiménez, L.G. and Rico-Méndez, F.G. (2011) Development and Validation of a Questionnaire to Identify Patients with Sleep Apnea in Mexican Population: Mexican Questionnaire to Identify Sleep Apnea. Sleep and Breathing, 15, 113-119. http://dx.doi.org/10.1007/s11325-010-0333-8

[53] Castorena-Maldonado, A., Torre-Bouscoulet, L., Meza-Vargas, S., Vázquez-García, J.C., López-Escárcega, E. and Pérez-Padilla, R. (2008) Preoperative Continuous Positive Airway Pressure Compliance in Children with Obstructive Sleep Apnea Syndrome: Assessed by a Simplified Approach. International Journal of Pediatric Otorhinolaryngology, 72, 1795-800. http://dx.doi.org/10.1016/j.ijporl.2008.08.016

[54] Labra, A., Huerta-Delgado, A.D., Gutiérrez-Sánchez, C., Cordero-Chacón, S.A. and Basurto-Madero, P. (2008) Uvulopalatopharyngoplasty and Uvulopalatal Flap for the Treatment of Snoring: Technique to Avoid Complications. Journal of Otolaryngology Head and Neck Surgery, 37, 256-269. 
[55] Valencia-Flores, M., Orea, A., Herrera, M., Santiago, V., Rebollar, V., Castaño, V.A., et al. (2004) Effect of Bariatric Surgery on Obstructive Sleep Apnea and Hypopnea Syndrome, Electrocardiogram, and Pulmonary Arterial Pressure. Obesity Surgery, 14, 755-762. http://dx.doi.org/10.1381/0960892041590773

[56] Loube, D.I., Gay, P.C., Strohl, K.P., Pack, A.I., White, D.P. and Collop, N.A. (1999) Indications for Positive Airway Pressure Treatment of Adult Obstructive Sleep Apnea Patients: A Consensus Statement. Chest, 115, 863-866. http://dx.doi.org/10.1378/chest.115.3.863

[57] Shapiro, G.K. and Shapiro, G.M. (2010) Factors That Influence CPAP Adherence: An Overview. Sleep and Breathing, 14, 323-335. http://dx.doi.org/10.1007/s11325-010-0391-y

[58] Aloia, M.S., Arnedt, J.T., Stanchina, M.Y. and Millman, R.P. (2007) How Early in Treatment Is PAP Adherence Established? Revisiting Night-to-Night Variability. Behavioral Sleep Medicine, 5, 229-240. http://dx.doi.org/10.1080/15402000701264005

[59] Somiah, M., Taxin, Z., Keating, J., Mooney, A.M., Norman, R.G., Rapoport, D.M., et al. (2012) Sleep Quality, ShortTerm and Long-Term CPAP Adherence. Journal of Clinical Sleep Medicine, 15, 489-500.

[60] Epstein, L.J., Kristo, D., Strollo, P.J., Friedman, N., Malhotra, A., Patil, S.P., et al. (2009) Clinical Guideline for the Evaluation, Management and Long-Term Care of Obstructive Sleep Apnea in Adults. Journal of Clinical Sleep, 5, 263276.

[61] La Piana, G.E., Scartabellati, A., Chiesa, L., Ronchi, L., Raimondi, P., Carro, M.A., et al. (2011) Long-Term Adherence to CPAP Treatment in Patients with Obstructive Sleep Apnea: Importance of Educational Program. Patient Preference and Adherence, 5, 555-562. http://dx.doi.org/10.2147/PPA.S24018

[62] Bollig, S.M. (2010) Encouraging CPAP Adherence: It Is Everyone’s Job. Respiratory Care, 55, 1230-1239.

[63] Glazer Baron, K., Gunn, H.E., Czajkowski, L.A., Smith, T.W. and Jones, C.R. (2012) Spousal Involvement in CPAP: Does Pressure Help? Journal of Clinical Sleep Medicine, 15, 147-153.

[64] Moran, A.M., Everhart, D.E., Davis, C.E., Wuensch, K.L., Lee, D.O. and Demaree, H.A. (2011) Personality Correlates of Adherence with Continuous Positive Airway Pressure (CPAP). Sleep and Breathing, 15, 687-694. http://dx.doi.org/10.1007/s11325-010-0422-8

[65] Aikens, J.E., Caruana-Montaldo, B., Vanable, P.A., Tadimeti, L. and Mendelson, W.B. (1999) MMPI Correlates of Sleep and Respiratory Disturbance in Obstructive Sleep Apnea. Sleep, 22, 362-369.

[66] Ekici, A., Ekici, M., Oğuztürk, O., Karaboğa, I., Cimen, D. and Senturk, E. (2013) Personality Profiles in Patients with Obstructive Sleep Apnea. Sleep and Breathing, 17, 315-310.

[67] Hayashida, K., Inoue, Y., Chiba, S., Yagi, T., Urashima, M, Honda, Y., et al. (2007) Factors Influencing Subjective Sleepiness in Patients with Obstructive Sleep Apnea Syndrome. Psychiatry Clinical Neurosciences, 61, 558-563. http://dx.doi.org/10.1111/j.1440-1819.2007.01707.x

[68] Sforza, E., de Saint Hilaire, Z., Pelissolo, A., Rochat, T. and Ibanez, V. (2002) Personality, Anxiety and Mood Traits in Patients with Sleep-Related Breathing Disorders: Effect of Reduced Daytime Alertness. Sleep Medicine Reviews, 2, 139-145. http://dx.doi.org/10.1016/S1389-9457(01)00128-9

[69] Pamidi, S., Knutson, K.L., Ghods, F. and Mokhlesi, B. (2011) Depressive Symptoms and Obesity as Predictors of Sleepiness and Quality of Life in Patients with REM-Related Obstructive Sleep Apnea: Cross-Sectional Analysis of a Large Clinical Population. Sleep, 12, 827-831. http://dx.doi.org/10.1016/j.sleep.2011.08.003

[70] Bardwell, W.A., Ancoli-Israel, S. and Dimsdale, J.E. (2007) Comparison of the Effects of Depressive Symptoms and Apnea Severity on Fatigue in Patients with Obstructive Sleep Apnea: A Replication Study. Journal of Affective Disorders, 97, 181-186. http://dx.doi.org/10.1016/j.jad.2006.06.013

[71] Harris, M., Glozier, N., Ratnavadivel, R. and Grunstein, R.R. (2009) Obstructive Sleep Apnea and Depression. Sleep Medicine Reviews, 13, 437-444. http://dx.doi.org/10.1016/j.smrv.2009.04.001

[72] Li, H.Y., Huang, Y.S., Chen, N.H., Fang, T.J., Liu, C.Y. and Wang, P.C. (2004) Mood Improvement after Surgery for Obstructive Sleep Apnea. Laryngoscope, 114, 1098-1102. http://dx.doi.org/10.1097/00005537-200406000-00026

[73] Poulet, C., Veale, D., Arnol, N., Lévy, P., Pepin, J.L. and Tyrrell, J. (2009) Psychological Variables as Predictors of Adherence to Treatment by Continuous Positive Airway Pressure. Sleep Medicine Reviews, 10, 993-999. http://dx.doi.org/10.1016/j.sleep.2009.01.007

[74] Sawyer, A.M., Deatrick, J.A., Kuna, S.T. and Weaver, T.E. (2010) Differences in Perceptions of the Diagnosis and Treatment of Obstructive Sleep Apnea and Continuous Positive Airway Pressure Therapy among Adherers and Nonadherers. Quality of Health Research, 20, 873-892. http://dx.doi.org/10.1177/1049732310365502

[75] Baron, K.G., Berg, C.A., Czajkowski, L.A., Smith, T.W., Gunn, H.E. and Jones, C.R. (2011) Self-Efficacy Contributes to Individual Differences in Subjective Improvements Using CPAP. Sleep and Breathing, 15, 599-606.

http://dx.doi.org/10.1007/s11325-010-0409-5 
[76] Sawyer, A.M., Canamucio, A., Moriarty, H., Weaver, T.E., Richards, K.C. and Kuna, S.T. (2011) Do Cognitive Perceptions Influence CPAP Use? Patient Education and Counseling, 85, 85-91. http://dx.doi.org/10.1016/j.pec.2010.10.014

[77] Tzischinsky, O., Shahrabani, S. and Peled, R. (2011) Factors Affecting the Decision to Be Treated with Continuous Positive Airway Pressure for Obstructive Sleep Apnea Syndrome. The Israel Medical Association Journal, 13, 413-419.

[78] Richards, D., Bartlett, D.J., Wong, K., Malouff, J. and Grunstein, R.R. (2007) Increased Adherence to CPAP with a Group Cognitive Behavioral Treatment Intervention: A Randomized Trial. Sleep, 30, 635-640.

[79] Tversky, A. and Kahneman, D. (1991) Loss Aversion in Riskless Choice: A Reference Dependent Model. Quarterly Journal of Economics, 106, 1039-1061. http://dx.doi.org/10.2307/2937956

[80] Trupp, R.J., Corwin, E.J., Ahijevych, K.L. and Nygren, T. (2011) The Impact of Educational Message Framing on Adherence to Continuous Positive Airway Pressure Therapy. Behavioral Sleep Medicine, 9, 38-52. http://dx.doi.org/10.1080/15402002.2011.533993

[81] Ellis, A. (1958) Rational Psychotherapy. Journal of General Psychology, 59, 35-49. http://dx.doi.org/10.1080/00221309.1958.9710170

[82] Lim, D.C. and Veasey, S.C. (2010) Neural Injury in Sleep Apnea. Current Neurology and Neuroscience Reports, 10, 47-52. http://dx.doi.org/10.1007/s11910-009-0078-6

[83] Sforza, E. and Roche, F. (2012) Sleep Apnea Syndrome and Cognition. Fontiers in Neurology Sleep and Chronobiology, 3, 87. http://dx.doi.org/10.3389/fneur.2012.00087

[84] Bucks, R.S., Olaithe, M. and Eastwood, P. (2012) Neurocognitive Function in Obstructive Sleep Apnea Meta-Review. Respirology, 17.

[85] Gozal, D., Capdevila, O.S. and Kheirandish-Gozal, L. (2008) Metabolic Alterations and Systemic Inflammation in Obstructive Sleep Apnea among Nonobese and Obese Prepubertal Children. American Journal of Respiratory and Critical Care Medicine, 177, 1142-1149. http://dx.doi.org/10.1164/rccm.200711-16700C

[86] Becker, H.F., Jerrentrup, A., Ploch, T., Grote, L.O., Penzel, T., Sullivan, C.E., et al. (2003) Effect of Nasal Continous Positive Airway Pressure Treatment on Blood Pressure in Patients with Obstructive Sleep Apnea. Circulation, 107, 6873. http://dx.doi.org/10.1161/01.CIR.0000042706.47107.7A

[87] Tuomilehto, H.P.I., Seppä, J.M., Partinen, M.M., et al., on behalf of the Kuopio Sleep Apnea Group (2009) Lifestyle Intervention with Weight Reduction: First-Line Treatment in Mild Obstructive Sleep Apnea. American Journal of Respiratory and Critical Care Medicine, 179, 320-327. http://dx.doi.org/10.1164/rccm.200805-669OC

[88] Tuomilehto, H., Seppä, J., Uusitupa, M., Peltonen, M., Martikainen, T., Sahlman, J., Kokkarinen, J., Randell, J., Pukkila, M., Vanninen, E., Tuomilehto, J. and Gylling, E. (2014) The Impact of Weight Reduction in the Prevention of the Progression of Obstructive Sleep Apnea: An Explanatory Analysis of a 5-Year Observational Follow-Up Trial. Sleep Medicine, 15, 329-335. http://dx.doi.org/10.1016/j.sleep.2013.11.786

[89] Ashrafian, H., Toma, T., Rowland, S.P., Harling, L., Tan, A., Efthimiou, E. and Athanasiou, T. (2014) Bariatric Surgery or Non-Surgical Weight Loss for Obstructive Sleep Apnoea? A Systematic Review and Comparison of MetaAnalyses. Obesity Surgery, in Press. http://dx.doi.org/10.1007/s11695-014-1533-2

[90] Bhattacharjee, H. and Aggarwal, S. (2013) Bariatric Surgery for Treatment of Obstructive Sleep Apnea. Journal of Internation Medical Sciences Academy, 26, 142-143.

[91] Baradaranfar, M.H., Edalatkhah, M., Dadgarnia, M.H., Atighechi, S., Behniafard, N., Mirvakili, A., Halvani, A., Baradaranfar, A. and Emami Meybodi, T. (2015) The Effect of Uvulopalatopharyngoplasty with Tonsillectomy in Patients with Obstructive Sleep Apnea. Indian Journal of Otolaryngology and Head and Neck Surgery, 67, 29-33. http://dx.doi.org/10.1007/s12070-014-0735-1

[92] Boyd, S.B., Walters, A.S., Song, Y. and Wang, L. (2013) Comparative Effectiveness of Maxillomandibular Advancement and Uvulopalatopharyngoplasty for the Treatment of Moderate to Severe Obstructive Sleep Apnea. Journal of Oral and Maxillofacial Surgery, 71, 743-751. http://dx.doi.org/10.1016/j.joms.2012.10.003

[93] Eastwood, P.R., Barnes, M., Walsh, J.H., et al. (2011) Treating Obstructive Sleep Apnea with Hypoglossal Nerve Stimulation. Sleep, 34, 1479-1486. http://dx.doi.org/10.5665/sleep.1380

[94] Certal, V.F., Zaghi, S., Riaz, M., Vieira, A.S., Pinheiro, C.T., Kushida, C. and Camacho, M. (2014) Hypoglossal Nerve Stimulation in the Treatment of Obstructive Sleep Apnea: A Systematic Review and Meta-Analysis. The Laryngoscope, 125, 1254-1264. http://dx.doi.org/10.1002/lary.25032

[95] Mador, M.J., Kufel, T.J., Magalang, U.J., Rajesh, S.K., Watwe, V. and Grant, B.J. (2005) Prevalence of Positional Sleep Apnea in Patients Undergoing Polysomnography. Chest, 128, 2130-2137. http://dx.doi.org/10.1378/chest.128.4.2130

[96] Heinzer, R.C., Pellaton, C., Rey, V., Rossetti, A.O., Lecciso, G., Haba-Rubio, J., Tafti, M. and Lavigne, G. (2012) Po- 
sitional Therapy for Obstructive Sleep Apnea: An Objective Measurement of Patients’ Usage and Efficacy at Home. Sleep Medicine, 13, 425-428. http://dx.doi.org/10.1016/j.sleep.2011.11.004

[97] Ravesloot, M.J.L., van Maanen, J.P., Dun, L. and de Vries, N. (2013) The Undervalued Potential of Positional Therapy in Position-Dependent Snoring and Obstructive Sleep Apnea-A Review of the Literature. Sleep and Breathing, 17, 39-49. http://dx.doi.org/10.1007/s11325-012-0683-5

[98] Afrashi, A., Ucar, Z.Z. (2015) Effect of Prone Positioning in Mild to Moderate Obstructive Sleep Apnea Syndrome. Sleep and Breathing, in Press. http://dx.doi.org/10.1007/s11325-014-0985-X

[99] Bidarian-Moniri, A., Nilsson, M., Attia, J. and Ejnell, H. (2015) Mattress and Pillow for Prone Positioning for Treatment of Obstructive Sleep Apnoea. Acta Oto-Laryngologica, 135, 271-276. http://dx.doi.org/10.3109/00016489.2014.968674

[100] Mehta, A., Qian, J., Petocz, P., Darendeliler, M.A. and Cistulli, P.A. (2001) A Randomized, Controlled Study of a Mandibular Advancement Splint for Obstructive Sleep Apnea. American Journal of Respiratory and Critical Care Medicine, 163, 1457-1461. http://dx.doi.org/10.1164/ajrccm.163.6.2004213

[101] Levendowski, D.J., Morgan, T.D., Patrickus, J.E., et al. (2007) In-Home Evaluation of Efficacy and Titration of a Mandibular Advancement Device for Obstructive Sleep Apnea. Sleep \& Breathing, 11, 139-147. http://dx.doi.org/10.1007/s11325-006-0094-6

[102] Carley, D.W., Olopade, C., Ruigt, G.S., et al. (2007) Efficacy of Mirtazapine in Obstructive Sleep Apnea Syndrome. Sleep, 30, 35-41.

[103] Kraiczi, H., Hedner, J., Dahlöf, P., Ejnell, H. and Carlson, J. (1999) Effect of Serotonin Uptake Inhibition on Breathing during Sleep and Daytime Symptoms in Obstructive Sleep Apnea. Sleep, 22, 61-67.

[104] Mason, M., Welsh, E.J. and Smith, I. (2013) Drug Therapy for Obstructive Sleep Apnoea in Adults. Cochrane Database of Systematic Reviews, in Press. http://dx.doi.org/10.1002/14651858.CD003002.pub3

[105] Fernández, A., Díez, J. and Chinarro, B. (2007) Dispositivos orales en el tratamiento del síndrome de apnea hipopneadel sueño. Revista de Patología Respiratoria, 10, 16-21.

[106] Sutherland, K., Vanderveken, O.M., Tsuda, H., Marklund, M., Gagnadoux, F., Kushida, C.A. and Cistulli, P.A. (2014) On behalf of the ORANGE-Registry. Oral Appliance Treatment for Obstructive Sleep Apnea: An Update. Journal of Clinical Sleep Medicine, 10, 215-227.

[107] Kline, C.E., Crowley, E.P., Ewing, G.B., et al. (2011) The Effect of Exercise Training on Obstructive Sleep Apnea and Sleep Quality: A Randomized Controlled Trial. Sleep, 34, 1631-1640. http://dx.doi.org/10.5665/sleep.1422

[108] Iftikhar, I.H., Kline, C.E. and Youngstedt, S.D. (2014) Effects of Exercise Training on Sleep Apnea: A Meta-Analysis. Lung, 192, 175-184. http://dx.doi.org/10.1007/s00408-013-9511-3 